\title{
LA CONSIDERACIÓN HISTÓRICA DE LOS HECHOS EDUCATIVOS
}

\section{THE HISTORICAL ACCOUNT OF THE EDUCATIONAL FACTS}

Mónica del Carmen Meza Mejía

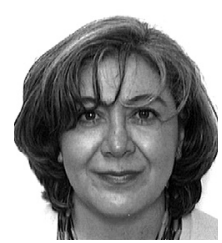

SNI. Doctora en Pedagogía, Universidad de Navarra, España. Maestra en Dirección de Empresas, IPADE. Maestra en Pedagogía, Universidad Panamericana. Licenciada en Pedagogía, Universidad Panamericana.

Correo electrónico: [mmeza@up.edu.mx].

\section{INTRODUCCIÓN}

Reflexionar sobre el fenómeno que compone el objeto de estudio de la Pedagogía, esto es la educación, remonta a algo tan antiguo como el hombre mismo. La educación por su carácter de hecho humano es también un hecho histórico. El estudio de los hechos humanos es campo de la Historia, la cual indaga y relata las cosas ocurridas, según su 
etimología griega ıбторı , que significa relato, narración y exposición de los acontecimientos pasados y dignos de memoria, sean públicos o privados $^{1}$.

La dimensión histórica de la educación como campo de estudio de la Pedagogía, investiga los hechos educativos pretéritos para conocer la realidad educativa con una doble finalidad: la de conocer cualquier realidad educativa de tiempos pasados; y la de situar los conocimientos históricos al servicio de los problemas actuales, pues «el hecho histórico no es puro pasado, sino un pasado que pervive en el presente» ${ }^{2}$; así se construye la Historia de la educación, un campo de conocimiento que estudia la realidad histórico-educativa a partir de la información que se conserva en diferentes fuentes, pues tal realidad del pasado «no se crea ni se inventa: simplemente se descubre, y, en todo caso, se recrea o se reconstruye y se interpreta» ${ }^{3}$.

La herencia del pasado de la realidad educativa, se le presenta al estudiante de la ciencia de la educación, como una disciplina de estudio que versa sobre los hechos educativos desde la dimensión histórica. Constituyen la base material del estudio histórico de la educación, las ideas, las personas, los sistemas, los estilos, las instituciones y los medios educativos, «teniendo bien presente, sin embargo, que son solo estos punto de partida para un conocimiento que, más allá de los límites institucionales, ha de abarcar los hechos y relaciones educativas implicados en la vida humana» ${ }^{4}$.

\section{SISTEMATIZACIÓN DE LA HISTORIA DE LA EDUCACIÓN}

El estudio de la Historia de la Educación se sistematiza atendiendo a las cosas ocurridas dentro de una línea de tiempo, porque la realidad

1 Diccionario de la Real Academia Española, en: [www.rae.es/recursos/diccionarios/ drae]. Recuperado: 17-XI-2015.

2 García Hoz, V. Principios de Pedagogía sistemática, p. 91.

3 Redondo, E., El estudio de la Historia de la educación, p. 11.

4 García Hoz, V. Op. cit., pp. 104-105. 
educativa pretérita se halla engarzada en el acontecer histórico total. Así, los múltiples textos sobre esta disciplina, narran cronológicamente los acontecimientos educativos pasados.

La educación primitiva.- En los tiempos primitivos, es decir, en el Paleolítico, no existe una dirección consciente de la educación hacia un fin preconcebido. Es, un nivel cultural en el que se puede identificar la educación con el proceso de crecimiento, de tal suerte que «la educación primitiva es una educación espontánea $»^{5}$.

La educación en las antiguas culturas orientales y occidentales.Las características educativas de estas culturas, como la maya, la azteca, la china, la egipcia, la india o la hebrea, por ejemplo, presentan un fuerte contraste con la greco-romana, como asevera Emilio Redondo. Estas culturas tienen características comunes, siguiendo al mismo autor referido: presentan un tradicionalismo y conservadurismo muy marcado. Un depósito doctrinal de contenido religioso, científico o cultural que resguarda quien posee el poder y el saber, usualmente el sacerdote, el curandero o el escriba. La educación sistematizada es exclusiva de grupos sociales privilegiados.

Grecia y Roma.- Esparta y Atenas representan dos tipos de educación que se diferencian en cuanto a sus fines. Para Esparta, el hombre sano y fuerte al servicio del Estado. Para Grecia, el perfeccionamiento del hombre como individuo, como ciudadano; para lo cual organiza todo el Estado para lograrlo. En Roma la familia era el ámbito y el agente educador por excelencia; un sentido de la educación más práctico que teórico. Por eso, «en Roma se encuentran pocas ideas pedagógicas y muchas acciones educativas» ${ }^{7}$.

La dimensión cristiana de la educación.- La cultura clásica grecorromana cobra un nuevo significado al incorporar los elementos culturales que configuran el cristianismo. El Magisterio de Cristo es universal y se dirige al hombre entero y, sobre todo, a su núcleo más íntimo.

5 Campillo Cuauhtli, H. Manual de Historia de la educación, p. 13.

6 Redondo, E. Op. cit., p. 53.

7 Ferrández, A. y Sarramona, J. La educación. Constantes y problemática actual, p. 101. 
No es pues una mera transmisión de saber, sino que se orienta a la realización del sujeto, como resultado de un proceso dinámico de formación personal, cuya raíz está en «la tensión dialéctica entre hombre y Cristo; entre sujeto individual y Verdad objetiva; entre Dios presente e iluminante y el yo obligado a buscarle en el amor» ${ }^{8}$.

El Medioevo.- A lo largo de la Edad Media se asimila la cultura clásica en una forma propia de pensar, creer y hacer. El saber medieval continúa el trayecto del saber antiguo, expresándose en poemas épicos que narran la historia de algunos pueblos de Europa. Es la época de las escuelas monacales, de las palatinas y de las gremiales; de las universidades; del trívium y del quadrivium; de la Filosofía escolástica y de la Teología. Es «el espíritu cristiano como una presencia viva que quiere inspirar toda la vida del hombre medieval; la unidad cristiana "que hace de todas las naciones europeas una comunidad internacional" $\gg$.

Renacimiento. Reforma y Contrarreforma.- El Renacimiento representa una exaltación del hombre. Es una renovación que busca interpretar la vida de forma distinta. Se manifiesta de formas diversa según el lugar en donde se desarrolle: Italia, España, Francia, Holanda, Alemania, Inglaterra. «Esta diversidad de enfoques no es más que la demostración definitiva de la originalidad de la época renacentista» ${ }^{10}$. Asimismo, las ideas renacentistas sobre el individuo derivan en la llamada Reforma, que cede al Estado el control de la escuela. «Pero no se trataba aún de una escuela pública, laica, obligatoria, universal y gratuita como se conoce actualmente» ${ }^{11}$. En respuesta, la denominada Contrarreforma, orienta la práctica educativa a la formación de la juventud cristiana, mediante la Ratio Studiorum.

Innovaciones y sistematización de las ideas educativas.- El siglo XVII busca cambiar el anterior sistema del proceso de enseñanza-aprendizaje. La Didáctica se torna el eje que inspira esta etapa de la

8 Gutiérrez Zuluaga, I. Historia de la educación, p. 144.

9 Capitán Díaz, A. Historia del pensamiento pedagógico en Europa. Desde sus orígenes al precientifismo pedagógico de J. F. Herbart, p. 171.

10 Ferrández, A. y Sarramona, J. Op. Cit., p. 123.

11 Gadotti, M. Historia de las ideas pedagógicas, p. 55. 
educación. Se pretende una enseñanza pansófica, integral y cíclica que integre el aprendizaje de todo aquello que sea útil para la vida, mediante la experiencia y la intuición. «Menos libros son necesarios, pues se tiene a disposición el libro vivo de la naturaleza» ${ }^{12}$. El siglo XVIII, por su parte, se caracteriza por la idea central de que «la sociedad progresará hasta alcanzar la felicidad si el hombre recibe una educación conveniente haciéndose "ilustrado" ${ }{ }^{13}$, mediante el conocimiento enciclopédico, síntesis del saber de la época. Métodos e instituciones como el kindergarten, son también parte de las ideas innovadoras en educación. Se reflexiona y se sistematiza el campo científico de la Pedagogía. Se discute su estatuto epistemológico y se perfilan los temas fundamentales de la educación: la educabilidad, el fin de la educación y los medios educativos, entre otros aspectos. «El interés por el método y la ciencia de la educación ${ }^{14}$, representan las innovaciones educativas de estos siglos que se cristalizan en la última mitad del siglo XIX.

Los horizontes pedagógicos en expansión.- Siguiendo a Lorenzo Luzuriaga $^{15}$, la Historia de la educación del siglo XX está llena de hechos educativos profusos y entrecruzados, que forman un cuadro muy complejo. ¿Qué define la educación del siglo pasado?, ¿los movimientos educativos de principios de siglo?, ¿la expansión de los sistemas escolarizados que sin precedente se desarrollan a partir de la década de los cincuenta?, ¿las corrientes psicológicas del aprendizaje?, ¿la incorporación de las tecnologías de la información y de la comunicación?, ¿el paradigma para el aprendizaje del siglo XXI, centrado en el estudiante? Se dice que la Historia es magistra vitae, maestra de vida, no obstante, «se quieren alcanzar ciertas metas que nos optimizan como personas y buscamos trazar aún los mejores caminos para lograr llegar a ellas» ${ }^{16}$.

12 Moreno G.; J. M., Poblador, A. y Del Río, D. Historia de la educación, p. 268.

$13 \quad$ Ibídem, p. 285.

14 Boyd, W. y King, E. J. Historia de la educación, p. 343.

15 Luzuriaga, L. Ideas pedagógicas del siglo XX.

16 Otero Urtaza, E. La Escuela de nuestro tiempo, p. 343. 


\section{A MODO DE CONCLUSIÓN}

La realidad de la educación pasada -o la presencia actual de la educación en tiempos pasados, como afirma García Hoz ${ }^{17}$ - es el objeto de estudio de la Historia del Educación, disciplina pedagógica y campo de investigación educativa. Proporciona al profesional de la educación una visión del pasado que le permite proyectar el futuro; por ello, conviene estudiar la realidad educativa desde la perspectiva histórica, dentro de su integral y natural contexto, clave de la significación y del sentido de los hechos pasados estudiados y una garantía de su correcta comprensión y valoración ${ }^{18}$. Así, en la Historia de la educación, la reinterpretación necesaria no se limita a clarificar el panorama retrospectivo, sino más bien, discernir en los tiempos pasados algunos precedentes de las nuevas y universales preocupaciones de la educación y la humanidad. "Estas preocupaciones se expresan ahora en términos muy diferentes de los que parecían aceptables cuando la tradición occidental de la educación estaba todavía circunscripta y tenía una visión provisional y cerrada del mundo» ${ }^{19}$.

\section{REFERENCIAS}

Boyd, W. y King, E.J. (1977). Historia de la educación. Buenos Aires: Huemul.

Campillo Cuauhtli, H. (1973). Manual de Historia de la educación. México: Fernández Editores.

17 Ibídem, p. 56.

18 Redondo, E. La Historia de la educación como realidad pretérita, como objeto de estudio y como disciplina científica, p. 42.

19 Boyd, W. y King, E.J. Historia de la educación, p. 447. 
Capitán Díaz, A. (1984). Historia del pensamiento pedagógico en Europa. Desde sus orígenes al precientifismo pedagógico de J. F. Herbart. Madrid: Dykinson.

Diccionario de la Real Academia Española, edición n. 23, publicada en octubre de 2014, en: [www.rae.es/recursos / diccionarios / drae].

Ferrández, A. y Sarramona, J. (1978). La educación. Constantes y problemática actual. Barcelona: CEAC.

Gadotti, M. (2000). Historia de las ideas pedagógicas. México: Siglo XXI.

García Hoz, V. (1960). Principios de Pedagogía sistemática. Madrid: Rialp.

Luzuriaga, L. (1964). Ideas pedagógicas del siglo XX. Buenos Aires: Losada.

Moreno G., J. M., Poblador, A. y Del Río (1978). Historia de la educación. Madrid: Paraninfo.

Otero Urtaza, E. (2004). «La Escuela de nuestro tiempo» en Del Pozo Andrés, M. del M. [ed.]. Teorías e instituciones contemporáneas de educación (pp. 339-355). Madrid: Biblioteca Nueva.

Redondo, E. (2001). «El estudio de la Historia de la educación» en Redondo García, E. [dir.], Introducción a la Historia de la educación (pp. 11-25). Barcelona: Ariel.

Redondo, E. (2001). «La Historia de la educación como realidad pretérita, como objeto de estudio y como disciplina científica» en Redondo García, E. [dir.]. Introducción a la Historia de la educación (pp. 27-52). Barcelona: Ariel. 